\title{
Technical note: Feasibility of near infrared transmittance spectroscopy to predict cheese ripeness
}

\author{
S. Currò, C. L. Manuelian, M. Penasa, M. Cassandro, and M. De Marchi ${ }^{1}$ \\ Department of Agronomy, Food, Natural Resources, Animals and Environment (DAFNAE), University of Padova, Viale dell'Università 16, \\ 35020 Legnaro (PD), Italy
}

\begin{abstract}
The aim of the study was to evaluate the feasibility of near infrared (NIR) transmittance spectroscopy to predict cheese ripeness using the ratio of water-soluble nitrogen (WSN) to total nitrogen (TN) as an index of cheese maturity (WSN/TN). Fifty-two Protected Designation of Origin cow milk cheeses of 5 varieties (Asiago, Grana Padano, Montasio, Parmigiano Reggiano, and Piave) and different ripening times were available for laboratory and chemometric analyses. Reference measures of WSN and TN were matched with cheese spectral information obtained from ground samples by a NIR instrument that operated in transmittance mode for wavelengths from 850 to 1,050 nm. Prediction equations for WSN and TN were developed using (1) cross-validation on the whole data set and (2) external validation on a subset of the entire data. The WSN/TN was calculated as ratio of predicted WSN to predicted TN in cross-validation. The coefficients of determination for WSN and TN were $>0.85$ both in cross- and external validation. The high accuracy of the prediction equations for WSN and TN could facilitate implementation of NIR transmittance spectroscopy in the dairy industry to objectively, rapidly, and accurately monitor the ripeness of cheese through WSN/TN.
\end{abstract}

Key words: chemometric, cheese quality, ripening time, water-soluble nitrogen

\section{Technical Note}

During ripening, cheese undergoes changes in organoleptic and chemical-physical attributes, promoting specific tastes, textures, and flavors. These characteristics are evaluated mainly by cheese factory technicians through sensory analysis, which is a subjective method. Variations during ripening depend on proteolysis, lipolysis, and glycolysis, with proteolysis being the

Received April 9, 2017.

Accepted August 2, 2017.

${ }^{1}$ Corresponding author: massimo.demarchi@unipd.it most important process (García-Palmer et al., 1997; McSweeney and Fox, 1997), indicating that chemical analysis is useful to assess cheese ripeness.

Cheese proteolysis involves the degradation of caseins, which are insoluble in many solvents, into large, medium-sized, and small peptides and free AA, which are soluble fractions. Consequently, peptides and free AA increase during the ripening period. These soluble fractions are determined through use of different solvents (McSweeney and Fox, 1997; Moatsou et al., 2002; Panari et al., 2003) and they can be used as objective indicators of cheese ripening. Traditionally, the ratio of water-soluble nitrogen (WSN) to total nitrogen (TN) has been adopted as an objective index to evaluate cheese ripeness (Innocente, 1997; Mazerolles et al., 2001; Moatsou et al., 2002). Chemical determination of TN and WSN is labor intensive and expensive, and it requires sample alteration. Therefore, the dairy industry and cheese technicians are interested in having a standardized, low-cost, fast, and reliable method to determine cheese ripeness.

Infrared spectroscopy offers a quick, easy to manage, low-cost, nondestructive, and chemical-free analysis, and it can be used to determine several traits concurrently. It is routinely used in the dairy industry to predict gross composition (fat, protein, and moisture content) of the products. Some authors have attempted to predict cheese age (Downey et al., 2005; Fagan et al., 2007), WSN (Karoui et al., 2006a,c; Fagan et al., 2007), TN (Karoui et al., 2006a,b), and WSN/TN (Mazerolles et al., 2001; Karoui et al., 2006a) using near infrared (NIR) reflectance (Downey et al., 2005; Karoui et al., 2006c) or mid-infrared reflectance (MIR; Mazerolles et al., 2001; Karoui et al., 2006a; Fagan et al., 2007) spectroscopy, but within a restricted ripening time $(<12 \mathrm{mo})$. The aim of the present study was to develop a NIR transmittance spectroscopy prediction model to objectively determine ripeness of several cheeses.

A total of 52 Protected Designation of Origin (PDO) cow milk cheeses of 5 varieties - Asiago, Grana Padano, Montasio, Parmigiano Reggiano, and Piave - were chosen according to the most produced, purchased, and ap- 
Table 1. Least squares means $\pm \mathrm{SE}(\mathrm{g} / 100 \mathrm{~g}$ of cheese) of moisture, fat, protein, and salt contents across Protected Designation of Origin (PDO) cheese variety and ripening time

\begin{tabular}{|c|c|c|c|c|c|}
\hline Item & $\mathrm{n}$ & Moisture & Fat & Protein & Salt \\
\hline \multicolumn{6}{|l|}{ PDO cheese variety } \\
\hline Asiago & 8 & $31.17 \pm 1.60^{\mathrm{a}}$ & $35.24 \pm 1.04^{\mathrm{d}}$ & $27.30 \pm 0.90^{\mathrm{a}}$ & $1.52 \pm 0.11^{\mathrm{a}}$ \\
\hline Grana Padano & 22 & $35.05 \pm 0.96^{\mathrm{a}}$ & $27.53 \pm 0.62^{\mathrm{a}}$ & $33.18 \pm 0.54^{\mathrm{b}}$ & $1.52 \pm 0.06^{\mathrm{a}}$ \\
\hline Montasio & 7 & $30.73 \pm 1.71^{\mathrm{a}}$ & $35.30 \pm 1.11^{\mathrm{cd}}$ & $28.11 \pm 0.96^{\mathrm{a}}$ & $1.60 \pm 0.11^{\mathrm{a}}$ \\
\hline Parmigiano Reggiano & 7 & $30.67 \pm 1.71^{\mathrm{a}}$ & $30.75 \pm 1.11^{\mathrm{abc}}$ & $33.77 \pm 0.96^{\mathrm{b}}$ & $1.75 \pm 0.11^{\mathrm{a}}$ \\
\hline Piave & 8 & $30.69 \pm 1.60^{\mathrm{a}}$ & $35.05 \pm 1.04^{\mathrm{bd}}$ & $29.52 \pm 0.90^{\mathrm{a}}$ & $1.65 \pm 0.11^{\mathrm{a}}$ \\
\hline \multicolumn{6}{|l|}{ Ripening time, mo } \\
\hline 1 to $<3$ & 13 & $36.89 \pm 1.03^{\mathrm{c}}$ & $28.72 \pm 1.21^{\mathrm{a}}$ & $29.94 \pm 0.90^{\mathrm{a}}$ & $1.41 \pm 0.08^{\mathrm{a}}$ \\
\hline 3 to $<12$ & 20 & $33.39 \pm 0.83^{\mathrm{b}}$ & $31.74 \pm 0.98^{\mathrm{ac}}$ & $29.87 \pm 0.73^{\mathrm{a}}$ & $1.59 \pm 0.06^{\mathrm{ac}}$ \\
\hline 12 to 40 & 19 & $28.86 \pm 0.85^{\mathrm{a}}$ & $32.75 \pm 1.00^{\mathrm{bc}}$ & $33.21 \pm 0.74^{\mathrm{b}}$ & $1.70 \pm 0.06^{\mathrm{bc}}$ \\
\hline
\end{tabular}

${ }^{a-d}$ Means with different letters within trait and item (PDO cheese variety or ripening time) are significantly different $(P<0.05)$.

preciated Italian PDO products (Gambelli et al., 1999; CLAL, 2015), including a wide ripening time (from 1 to 40 mo; Table 1). Samples were acquired from commercial stores and from the dairy industry, and they were sent at refrigeration temperature to the laboratory of the Department of Agronomy, Food, Natural Resources, Animals and Environment of the University of Padova (Legnaro, Italy) for analyses. After removal of the rind ( $1.5 \mathrm{~cm}$ from the outer surface), each cheese sample was homogenized by using a knife mill (Retsch Grindmix GM200, Retsch GmbH \& Co, Haan, Germany). Ground samples were kept in a sealed plastic bag at $4^{\circ} \mathrm{C}$ and analyzed within $24 \mathrm{~h}$ to avoid variations in cheese composition depending on moisture loss.

Cheese moisture, protein, fat, and salt amounts were determined using FoodScan Dairy Analyzer (Foss Electric A/S, Hillerød, Denmark) precalibrated with Foss Artificial Neutral Networks Dairy Calibration. The WSN fraction was obtained with a dilution of $4 \mathrm{~g}$ of each ground sample into $100 \mathrm{~mL}$ of distilled water at $40^{\circ} \mathrm{C}$ (Gazzetta Ufficiale, 1986) and homogenized using an Ultra Turrax PT 2500 homogenizer (Polytron Kinetica, West Yorkshire, UK) at $242 \times g$ for $30 \mathrm{~s}$. After an overnight rest, the sample was filtered and analyzed by using the Kjeldahl method and a Tecator Kjeltek 2300 Analyzer Unit (Foss Electric A/S). The amount of TN was determined using the Kjeldahl method by digesting $1 \mathrm{~g}$ of the ground sample (Gazzetta Ufficiale, 1986). The WSN/TN ratio was used as index of cheese ripening. Spectra of ground cheeses were recorded by means of FoodScan Dairy Analyzer (Foss Electric A/S), which operated in transmittance mode from 850 to 1,050 nm every $2 \mathrm{~nm}$. Each spectrum was obtained by averaging 16 sub-spectra recorded at different points during automatic rotation of the Petri cup $(10 \mathrm{~cm}$ internal diameter) filled with the sample. Spectrum was recorded as $\log (1 /$ transmittance $)$. An ANOVA followed by Bonferroni's test for multiple comparisons was performed using SAS software (version 9.4; SAS Institute
Inc., Cary, NC) to test whether moisture, protein, fat, and salt contents differed across cheese varieties and ripening time. Significance was set at $P<0.05$, unless otherwise indicated.

Prediction equations for TN and WSN were developed for each trait using (1) the whole data set ( $\mathrm{n}=$ 52 ) or (2) a subset of the entire data (calibration set) using modified partial least squares (MPLS) regression analysis (WinISI III v. 1.60; Foss and Infrasoft International LLC, State College, PA), which is more accurate and stable than the standard partial least squares approach (González-Martín et al., 2011). The algorithm for MPLS considers the standardized residuals after each factor before moving to the next factor (Meagher et al., 2007). The predicted WSN/TN was calculated as ratio of predicted WSN to predicted $\mathrm{TN}$, which was obtained through the model developed for each trait on the whole data set. For an easy implementation of WSN/TN in the dairy industry, a prediction equation for WSN/TN was also developed. The goodness of prediction equations obtained for the whole data set were assessed through cross-validation, where one-fifth of the samples, randomly chosen, were temporarily removed from the initial data set. This procedure was repeated until all subgroups were treated both as calibration and prediction set. The goodness of the prediction equations developed using the calibration set were evaluated by means of external validation. To create the calibration and validation set, the complete data set was split into 2 subsets with comparable mean and standard deviation (SD) for each trait. The calibration set ( $75 \%$ of the samples) was used to develop the prediction models, and the validation set $(25 \%$ of the samples) was used to validate the calibration. Several combinations of scattering correction [no correction; detrend (D); standard normal variate (SNV); SNV + D; and multiplicative scatter correction (MSC)] and mathematical treatment $(0,0,1,1 ; 1,4,4,1 ; 1,8,8,1$; $2,5,5,1$; and $2,10,10,1$, with the first digit representing 
the number of the derivative, the second the gap over which the derivative is calculated, the third the number of data points in the first smoothing, and the fourth the number of data points in the second smoothing) were applied to raw spectra to improve the accuracy of calibration. A sample was defined as an outlier and removed from the data set when the difference between predicted and reference value was greater than 2.5 SD (T-statistic). The best prediction equation was chosen with respect to the number of latent factors; the standard error of calibration, cross-validation, and external validation; the coefficient of determination of calibration, cross-validation $\left(\mathbf{R}^{2} \mathbf{C V}\right)$, and external validation $\left(\mathbf{R}_{\mathrm{ExV}}^{2}\right)$; and residual predictive deviation of cross-validation $\left(\mathbf{R P D} \mathbf{D}_{\mathbf{C V}}\right)$ and of external validation $\left(\mathbf{R P D} \mathbf{D}_{\mathrm{ExV}}\right)$, calculated as the ratio of the SD of the trait to the SE of cross validation and external validation, respectively (Williams and Sobering, 1993). Moreover, normality of residuals of the predicted models was investigated, and the bias (i.e., the average of the differences between the reference value and the respective predicted value for each observation) was calculated. A $t$-test was used to determine whether the bias differed statistically from zero.

All cheese varieties showed a similar composition (Table 1 ), with some differences $(P<0.05)$ in terms of fat and protein contents, in accordance with data reported by Manuelian et al. (2017) for the same Italian PDO cheeses. Despite not being significant, the slightly greater moisture content of Grana Padano compared with other cheeses was due to the inclusion of samples with a ripening time less than 9 mo, which is the minimum time required to meet the PDO European regulation [Reg. (CE) n. 1107/96; Reg. (UE) n. 584/11]. As expected, moisture content decreased with ripening time $(P<0.05)$, whereas fat, protein, and salt contents increased (Table 1 ), in agreement with findings of Hickey et al. (2013) in Cheddar cheese, and Buffa et al. (2001) in goat cheeses. Ripening time was strongly negatively correlated with moisture (correlation coefficient, $\mathrm{r}=-0.65 ; P<0.001)$ and strongly positively correlated with WSN/TN and WSN $(\mathrm{r}=0.79$ and 0.82 , respectively; $P<0.001$ ), which agreed with Woodcock et al. (2008). The increase of WSN/TN during ripening has been also reported in sheep cheese by Macedo and Malcata (1997), and in Montasio PDO cheese by Innocente (1997). Moisture was strongly negatively associated with fat $(\mathrm{r}=-0.72 ; P<0.001)$, WSN $(\mathrm{r}=-0.60$; $P<0.001)$, and WSN $/ \mathrm{TN}(\mathrm{r}=-0.66 ; P<0.001)$, in agreement with Manuelian et al. (2017), who observed an increase of fat, protein, and mineral contents in cow milk cheeses when cheese moisture decreased. We determined that TN was moderately positively correlated with WSN/TN ( $\mathrm{r}=0.44 ; P<0.001)$, which disagrees with Karoui et al. (2006a), who did not observe a correlation between these 2 traits in Emmental cheese. On the other hand, like Karoui et al. (2006a), we observed a very strong and positive correlation between WSN and WSN/TN $(\mathrm{r}=0.96 ; P<0.001)$.

Outliers for the whole data set and the subset data for external validation were less than $12 \%$, and latent factors ranged from 7 to 10, in agreement with Karoui et al. (2006a,b). The best calibration statistics for TN and WSN in both cross-validation and external validation were obtained using SNV and MSC scattering corrections, and first derivative. For all prediction models, residuals were normally distributed and bias did not differ from zero. Fagan et al. (2007) also reported that the best results for WSN were achieved using first derivative with MIR spectroscopy, whereas GonzálezMartín et al. (2008) obtained the best results with no scatter correction for $\mathrm{CP}$ of cow, sheep, and goat milk cheeses calculated as $\mathrm{TN} \times 6.38$, and predicted by NIR reflectance spectroscopy. The $\mathrm{R}_{\mathrm{CV}}^{2}$ and $\mathrm{R}_{\mathrm{ExV}}^{2}$ were 0.93 and 0.85 for WSN, and 0.99 and 0.95 for TN, respectively, which imply good and excellent prediction models, respectively (Karoui et al., 2006b). Prediction results for TN were better than those reported by González-Martín et al. (2008) for $\mathrm{CP}\left(\mathrm{R}_{\mathrm{CV}}^{2}=0.78\right)$ using a NIR reflectance bundle fiber optic probe, and by Karoui et al. (2006a,b) for Emmental cheese using MIR $\left(\mathrm{R}_{\mathrm{CV}}^{2}=0.62 ; \mathrm{R}_{\mathrm{ExV}}^{2}=0.62\right.$ to 0.74$)$ and NIR reflectance spectroscopy $\left(\mathrm{R}_{\mathrm{CV}}^{2}=0.82 ; \mathrm{R}_{\mathrm{ExV}}^{2}=0.86\right)$. Also, our $\mathrm{R}^{2}{ }_{\mathrm{CV}}$ for WSN calibration model was better than that reported by Fagan et al. (2007) for Cheddar cheese using $\operatorname{MIR}\left(\mathrm{R}_{\mathrm{CV}}^{2}=0.63\right)$ and by Karoui et al. (2006b) using NIR reflectance $\left(\mathrm{R}_{\mathrm{CV}}^{2}=0.77\right)$ and MIR spectroscopy $\left(\mathrm{R}_{\mathrm{CV}}^{2}=0.80\right)$, and $\mathrm{R}_{\mathrm{ExV}}^{2}$ was similar to those reported by Karoui et al. (2006b) using NIR reflectance and MIR spectroscopy $\left(\mathrm{R}_{\mathrm{ExV}}^{2}=0.88\right)$. McKenna (2001) demonstrated that NIR transmittance spectroscopy performed better than NIR reflectance spectroscopy for moisture analysis of Edam, Gouda, Brie, Colby, and Cheddar cheeses. In addition, the monitoring of cheese ripening with NIR transmittance technology is faster than that achievable using MIR spectroscopy, because of the easier sample preparation (Woodcock et al., 2008). Prediction equations developed in the present study showed residual predictive deviation of at least 2.5, which is the threshold at which a prediction equation is considered adequate for analytical purposes (Sinnaeve et al., 1994). The RPD $\mathrm{CV}_{\mathrm{CV}}$ for WSN (3.89) and TN (8.50) calculated on the whole data set were greater than the RPD $\mathrm{ExV}_{\mathrm{EV}}$ for WSN (2.50) and TN (4.37) calculated on the external validation subset. Nevertheless, the fitting statistics for the predicted models indicated that cross-validation and external validation performed similarly, confirming the robustness of NIR transmit- 
(a)

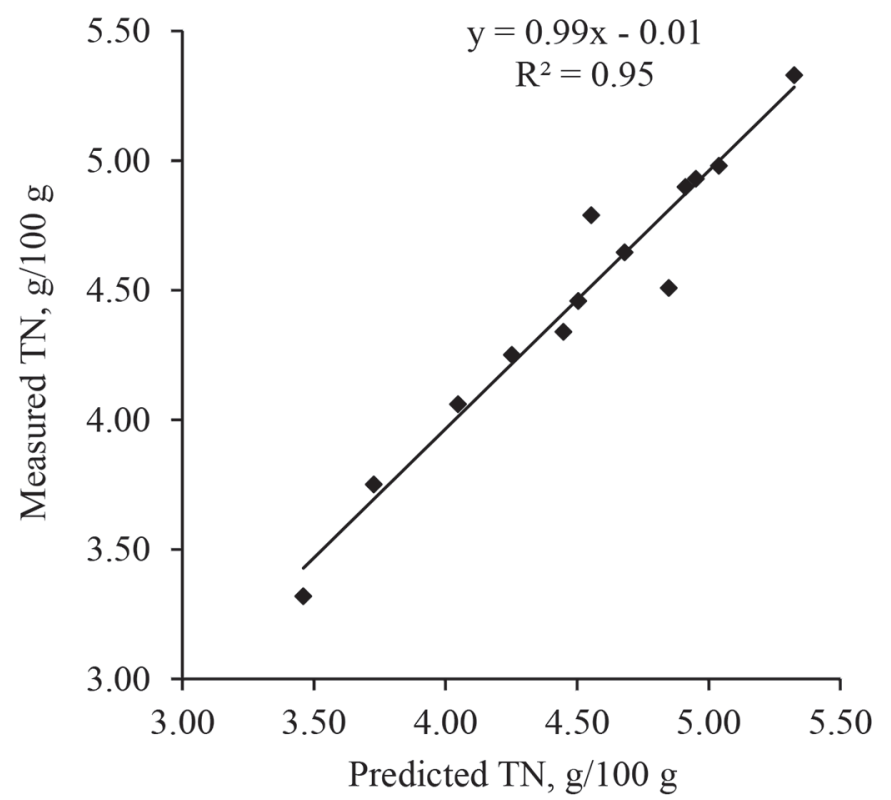

(b)

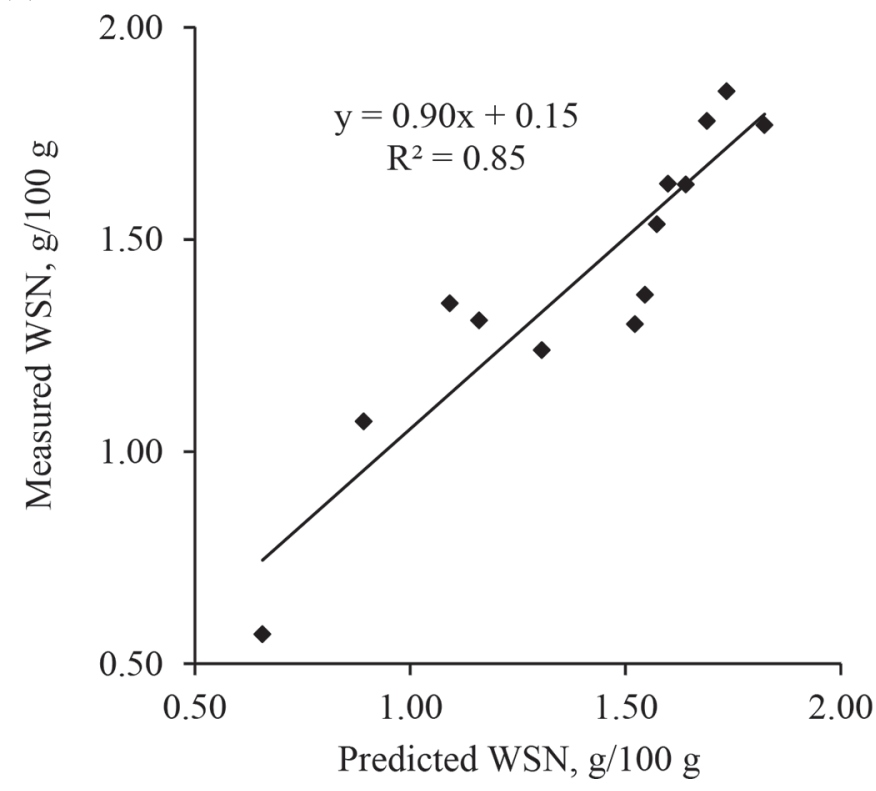

Figure 1. Linear regression plot of measured versus predicted (a) total nitrogen (TN), and (b) water-soluble nitrogen (WSN) in the external validation approach $(\mathrm{n}=13)$.

tance models previously reported by González-Martín et al. (2014). Our RPD values for TN were greater than-and those for WSN were similar to - those reported by Karoui et al. (2006b) for the same traits predicted using NIR reflectance and MIR spectroscopy. The differences in terms of accuracy could be explained by the wider range of variation that resulted from our study because of the inclusion of several cheese varieties in the analysis (Blanco and Villarroya, 2002; Kamruzza-

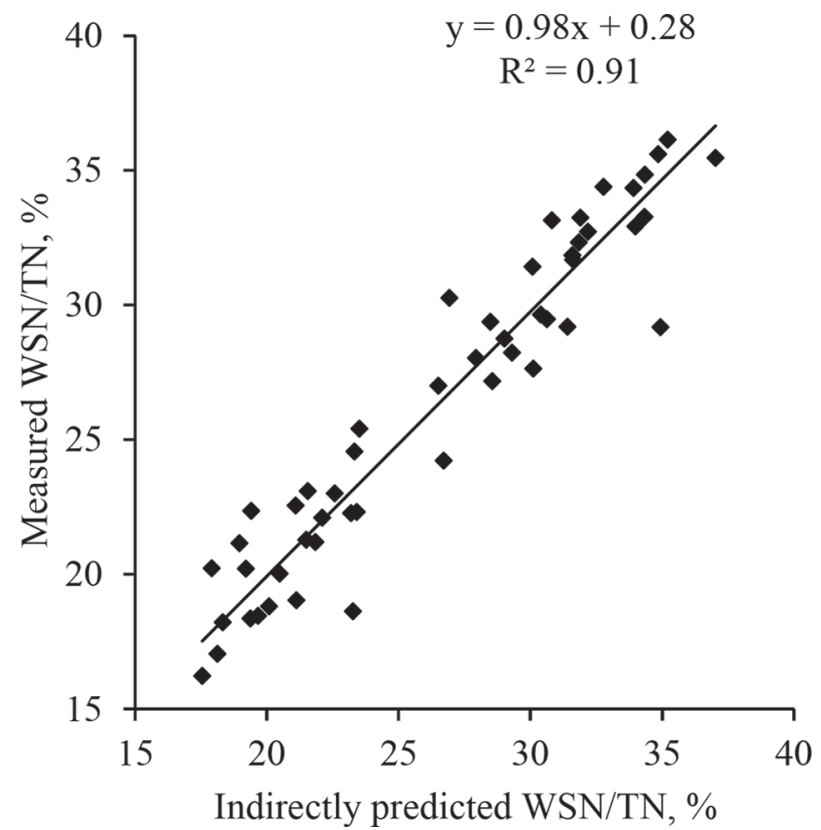

Figure 2. Linear regression plot of measured versus indirectly predicted water-soluble nitrogen to total nitrogen ratio (WSN/TN) in the cross-validation approach $(\mathrm{n}=52)$.

man et al., 2012) and the longer ripening time (greater than $12 \mathrm{mo}$ ) used to build prediction models. Karoui et al. (2006b) dealt with only Emmental cheese, which exhibited a range of $0.69 \mathrm{~g} / 100 \mathrm{~g}$ for $\mathrm{TN}$, whereas we analyzed 5 different cheese varieties, which provided a range of $2.4 \mathrm{~g} / 100 \mathrm{~g}$ for $\mathrm{TN}$.

The linear regression of measured versus predicted values of TN $(r=0.97)$ and WSN $(r=0.92)$ for the external validation data set are represented in Figure 1. The model for TN explained a greater percentage of the variance than the model for WSN, which could be related to the greater concentration of TN $(4.52 \mathrm{~g} / 100 \mathrm{~g})$ than WSN $(1.21 \mathrm{~g} / 100 \mathrm{~g})$. The linear regression of the measured versus indirectly predicted WSN/TN $(\mathrm{r}=$ 0.95 ) for the whole data set was very accurate (Figure 2 ); residuals were normally distributed and bias did not differ from zero. As expected, the prediction equation for WSN/TN developed using the original data (results not shown) was in agreement with indirectly predicted WSN/TN calculated as the ratio of predicted WSN to predicted TN. In addition, the goodness-of-fit statistics of the MPLS model for directly predicted WSN/TN were similar in the whole data set $\left(\mathrm{R}_{\mathrm{CV}}^{2}=0.90 ; \mathrm{RPD}_{\mathrm{CV}}\right.$ $=3.14)$ and in the subset for external validation $\left(\mathrm{R}_{\mathrm{ExV}}^{2}\right.$ $\left.=0.92 ; \mathrm{RPD}_{\mathrm{ExV}}=3.00\right)$. These results were also similar to those obtained for the WSN prediction equations, which agreed with the very strong linear correlation observed between WSN and WSN/TN. Karoui et al. (2006a) also reported a high and similar accuracy of 
the WSN/TN prediction model $\left(\mathrm{R}_{\mathrm{CV}}^{2}=0.83 ; \mathrm{RPD}_{\mathrm{CV}}\right.$ $\left.=2.81 ; \mathrm{R}_{\mathrm{ExV}}^{2}=0.90 ; \mathrm{RPD}_{\mathrm{ExV}}=2.94\right)$.

In conclusion, our results demonstrated the feasibility of NIR transmittance spectroscopy to predict cheese ripeness with great accuracy, using both crossvalidation and external validation approaches. Findings of the present study could facilitate implementation of this technology at the industry level to objectively and rapidly assess the cheese ripening process and thus have a quality indicator of the final product.

\section{ACKNOWLEDGMENTS}

The authors thank Luciano Magro (Department of Agronomy, Food, Natural Resources, Animals and Environment, University of Padova) for laboratory analyses.

\section{REFERENCES}

Blanco, M., and I. Villarroya. 2002. NIR spectroscopy: A rapid-response analytical tool. Trends Analyt. Chem. 21:240-250.

Buffa, M. N., A. J. Trujillo, M. Pavia, and B. Guamis. 2001. Changes in textural, microstructural, and colour characteristics during ripening of cheeses made from raw, pasteurized or high-pressuretreated goats' milk. Int. Dairy J. 11:927-934.

CLAL. 2015. La classificazione dei formaggi. Accessed Feb. 10, 2017. http://www.clal.it/downloads/schede/CLAL-Classificazione _formaggi_italiani.pdf.

Downey, G., E. Sheehan, C. Delahunty, D. O'Callaghan, T. Guinee, and V. Howard. 2005. Prediction of maturity and sensory attributes of Cheddar cheese using near-infrared spectroscopy. Int. Dairy J. 15:701-709.

Fagan, C. C., C. P. O'Donnell, D. J. O'Callaghan, G. Downey, E. M. Sheehan, C. M. Delahunty, C. Everard, T. P. Guinee, and V. Howard. 2007. Application of mid-infrared spectroscopy to the prediction of maturity and sensory texture attributes of Cheddar cheese. J. Food Sci. 72:130-137.

Gambelli, L., P. Belloni, G. Ingrao, L. Pizzoferrato, and G. P. Santaroni. 1999. Minerals and trace elements in some Italian dairy products. J. Food Compos. Anal. 12:27-35.

García-Palmer, F. J., N. Serra, A. Palou, and M. Gianotti. 1997. Free amino acids as indices of Mahón cheese ripening. J. Dairy Sci. 80:1908-1917.

Gazzetta Ufficiale. 1986. Metodi ufficiali di analisi per i formaggi. G.U. L229. Ministero dell'Agricoltura e delle Foreste (MAF), Rome, Italy.

González-Martín, I., C. González-Pérez, J. M. Hernández-Hierro, and J. M. González-Cabrera. 2008. Use of NIRS technology with a remote reflectance fibre-optic probe for predicting major components in cheese. Talanta 75:351-355.

González-Martín, I., J. M. Hernández-Hierro, C. González-Pérez, I. Revilla, A. Vivar-Quintana, and I. Lobos Ortega. 2014. Potential of near infrared spectroscopy for the analysis of volatile components in cheeses. Food Sci. Technol. 55:666-673.

González-Martín, I., P. Severiano-Pérez, I. Revilla, A. M. VivarQuintana, J. M. Hernández-Hierro, C. González-Pérez, and I. A.
Lobos-Ortega. 2011. Prediction of sensory attributes of cheese by near-infrared spectroscopy. Food Chem. 127:256-263.

Hickey, D. K., T. P. Guinee, J. Hou, and M. G. Wilkinson. 2013. Effects of variation in cheese composition and maturation on water activity in Cheddar cheese during ripening. Int. Dairy J. 30:53-58.

Innocente, N. 1997. Free amino acids and water-soluble nitrogen as ripening indices in Montasio cheese. Lait 77:359-369.

Kamruzzaman, M., G. Elmasry, D. W. Sun, and P. Allen. 2012. Nondestructive prediction and visualization of chemical composition in lamb meat using NIR hyperspectral imaging and multivariate regression. Innov. Food Sci. Emerg. Technol. 16:218-226.

Karoui, R., A. M. Mouazen, É. Dufour, L. Pillonel, D. Picque, J.-O. Bosset, and J. De Baerdemaeker. 2006a. Mid-infrared spectrometry: A tool for the determination of chemical parameters in Emmental cheeses produced during winter. Lait 86:83-97.

Karoui, R., A. M. Mouazen, É. Dufour, L. Pillonel, E. Schaller, J. De Baerdemaeker, and J.-O. Bosset. 2006c. Chemical characterisation of European Emmental cheeses by near infrared spectroscopy using chemometric tools. Int. Dairy J. 16:1211-1217.

Karoui, R., A. M. Mouazen, É. Dufour, L. Pillonel, E. Schaller, D. Picque, J. De Baerdemaeker, and J.-O. Bosset. 2006b. A comparison and joint use of NIR and MIR spectroscopic methods for the determination of some parameters in European Emmental cheese. Eur. Food Res. Technol. 223:44-50.

Macedo, A. C., and F. X. Malcata. 1997. Secondary proteolysis in Serra cheese during ripening and throughout the cheese-making season. Zeitschrift für Lebensmittel-Untersuchung und-Forschung A 204:173-179.

Manuelian, C. L., S. Currò, M. Penasa, M. Cassandro, and M. De Marchi. 2017. Characterization of major and trace minerals, fatty acid composition, and cholesterol content of Protected Designation of Origin cheeses. J. Dairy Sci. 100:3384-3395. https://doi.org/10 .3168/jds.2016-12059.

Mazerolles, G., M.-F. Devaux, G. Duboz, M.-H. Duployer, N. Mouhous Riou, and É. Dufour. 2001. Infrared and fluorescence spectroscopy for monitoring protein structure and interaction changes during cheese ripening. Lait 81:509-527.

McKenna, D. 2001. Measuring moisture in cheese by near infrared absorption spectroscopy. J. AOAC Int. 84:623-628.

McSweeney, P. L. H., and P. F. Fox. 1997. Chemical methods for the characterization of proteolysis in cheese during ripening. Lait $77: 41-76$.

Meagher, L. P., S. E. Holroyd, D. Illingworth, F. van de Ven, and S. Lane. 2007. At-line near-infrared spectroscopy for prediction of the solid fat content of milk fat from New Zealand butter. J. Agric. Food Chem. 55:2791-2796.

Moatsou, G., T. Massouras, I. Kandarakis, and E. Anifantakis. 2002. Evolution of proteolysis during the ripening of traditional Feta cheese. Lait 82:601-611.

Panari, G., P. Mariani, A. Summer, R. Guidetti, and M. Pecorari 2003. Variazione della composizione e andamento della proteolisi del Parmigiano-Reggiano nel corso della maturazione in riferimento al profilo (centro e periferia) della forma. Sci. Tecn. Latt. Cas. 54:199-212.

Sinnaeve, G., P. Dardenne, R. Agneessens, and R. Biston. 1994. The use of near infrared spectroscopy for the analysis of fresh grass silage. J. Near Infrared Spectrosc. 2:79-84.

Williams, P. C., and D. C. Sobering. 1993. Comparison of commercial near infrared transmittance and reflectance instruments for analysis of whole grains and seeds. J. Near Infrared Spectrosc. 1:25-32.

Woodcock, T., C. C. Fagan, C. P. O'Donnell, and G. Downey. 2008. Application of near and mid-infrared spectroscopy to determine cheese quality and authenticity. Food Bioproc. Techol. 1:117-129. 